\title{
Infective Endocarditis in Tetralogy of Fallot Complicating Brain Abscess-A Case Report
}

\author{
Ramachandran Muthiah \\ Port Trust Hospital, Thoothukudi, India \\ Email: cardioramachandran@yahoo.co.uk
}

How to cite this paper: Muthiah, R. (2019) Infective Endocarditis in Tetralogy of Fallot Complicating Brain Abscess-A Case Report. Case Reports in Clinical Medicine, $\mathbf{8}$, 105-126.

https://doi.org/10.4236/crcm.2019.85013

Received: March 29, 2019

Accepted: May 12, 2019

Published: May 15, 2019

Copyright (c) 2019 by author(s) and Scientific Research Publishing Inc. This work is licensed under the Creative Commons Attribution International License (CC BY 4.0).

http://creativecommons.org/licenses/by/4.0/

(c) (i) Open Access

\begin{abstract}
Aim: To report a case of solitary, parietal lobe abscess in a boy, aged 16 years in Tetralogy of Fallot. Introduction: Infective endocarditis is a serious and fatal complication in congenital heart disease. Following bacterial endocarditis, ventricular septal defect (VSD) and Tetralogy of Fallot (TOF) have less morbidity and higher survival rate in children. Neurological complications were recognized in $20 \%$ of cases and brain abscess is a serious infection of brain parenchyma as a result of seeding of infective pathogens in the shunted blood from the right side of the heart. Case Report: A 16 year old boy had Tetralogy of Fallot, presented with altered sensorium of sudden onset. Echocardiography revealed a large vegetation, attached to the ventricular septum and a large VSD with overriding of aorta. CT brain revealed a large abscess cavity in the parietal lobe, which was evacuated by aspiration and treated with antibiotics. Conclusion: Any patient presented with altered sensorium in cyanotic congenital heart disease must be evaluated with CT scanning for brain abscess and also check hematocrit to rule out hyperviscosity syndrome. Lumbar puncture has been considered hazardous in patients with brain abscess and usually performed under a strong suspicion of meningitis or ventriculitis in the absence of increased intracranial pressure.
\end{abstract}

\section{Keywords}

Tetralogy of Fallot, Vegetation, Brain Abscess, Five Component Therapy, Surgical Aspiration

\section{Introduction}

Cyanotic congenital heart disease is characterized by intracardiac right-to-left shunting of unsaturated blood and its distribution into the systemic circulation resulting in arterial hypoxaemia, leading to pulmonary vasoconstriction, poly- 
cyathaemia, coagulopathy, infective endocarditis (IE) and brain abscess due to increased risk of paradoxical embolism. Cyanotic heart disease accounts for $12.8 \%-69.4 \%$ of all cases of brain abscess with the incidence being higher in children [1] [2]. The risk of brain abscess complicating cyanotic CHD (congenital heart disease) is inconstant, but is more common after two years of age and increases consistently until the age of 12 years. Of all the patients with brain abscess and cyanotic congenital heart disease, TOF (Tetralogy of Fallot) is the most common in association (13\% - 70\%) of cases [3] [4] [5] [6] [7].

Infective endocarditis typically presents more insidiously in patients with congenital heart disease. The risk of infective endocarditis in cyanotic CHD is more than six times the risk compared to those in acyanotic CHD. Patients with congenital heart disease have structural changes that create turbulence and shear force in blood blow that disrupts the endocardium, exposing the subendocardial collagen and extracellular matrix. The resultant inflammation causes endothelial cells to express $\beta_{1}$ integrins, which bind circulating fibronectin to the endothelial surface and promote scar formation. During the healing process, production of tissue factor, deposition of fibrin, and platelet adherence lead to hemostasis and pathogenic organisms may settle in and infect the endocardium in these scarred areas. With sequestration and limited blood supply to a damaged area, formation of vegetation and/or abscess may occur. These friable vegetations have the capability of causing emboli, which may cause distal abscess formation, especially in the brain and so this case had been reported.

\section{Case Report}

A 16 year old cyanotic male was admitted with altered sensorium in the intensive care unit. He was diagnosed as Tetralogy of Fallot and advised corrective surgery earlier. He was afebrile and his pulse rate was $64 \mathrm{bpm}$ and blood pressure 100/60 mmHg. He had headache, vomiting episodes and stiff neck for the past 3 days. Blood chemistry revealed normal. ECG and X-ray chest as in Figure 1 (boot-shaped heart) were consistent with Tetralogy of Fallot. Physical examination revealed uniform central cyanosis with clubbing, $2 / 6$ systolic murmur in the left second intercostal space and a single second sound. Echocardiography revealed a non-restrictive, large, malaligned VSD (ventricular septal defect), biventricular aorta as shown in Figure 2. A large vegetation was attached to the crest of interventricular septum (IVS) as in Figure 3 and Figure 4.

CT (computed tomography) brain revealed a large abscess cavity in the parietal region as in Figures 5-7. The abscess was aspirated via burr-hole and cultures were found to be negative. He was given ceftriaxone $1 \mathrm{~g}$ IV twice daily, amickacin $500 \mathrm{mg}$ IV twice daily with tablet phenytoin sodium $100 \mathrm{mg}$ twice daily for 2 weeks. He was symptom free and advised periodic follow up.

On 1 year follow up, the patient was asymptomatic without any sequelae and advised corrective surgery for the cardiac anomaly at the earliest. 


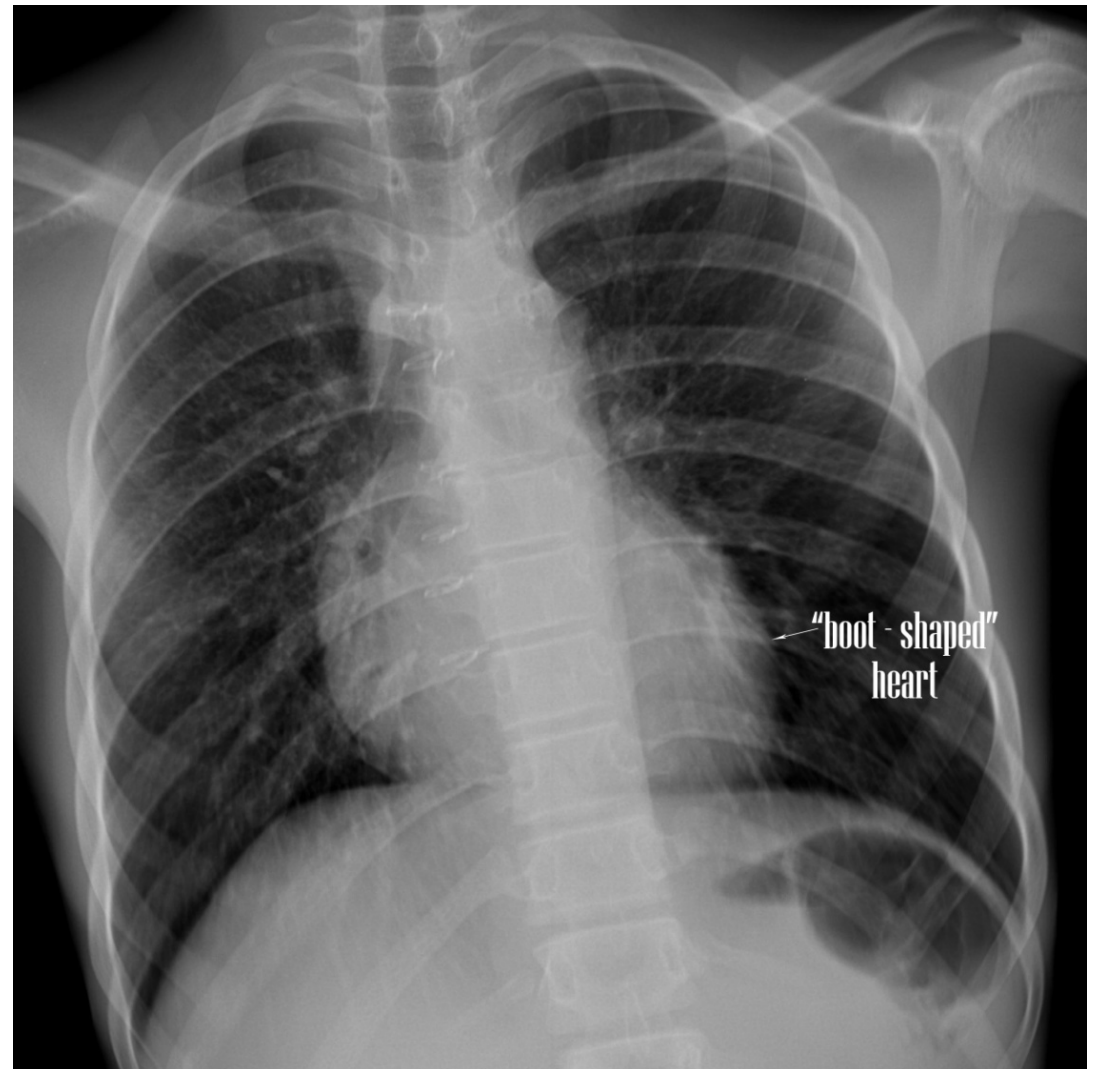

Figure 1. X-ray chest PA (Postero-anterior) view showing the "boot-shaped heart" (arrow) of tetralogy of Fallot with oligemic lung fields in a 16 year old boy.

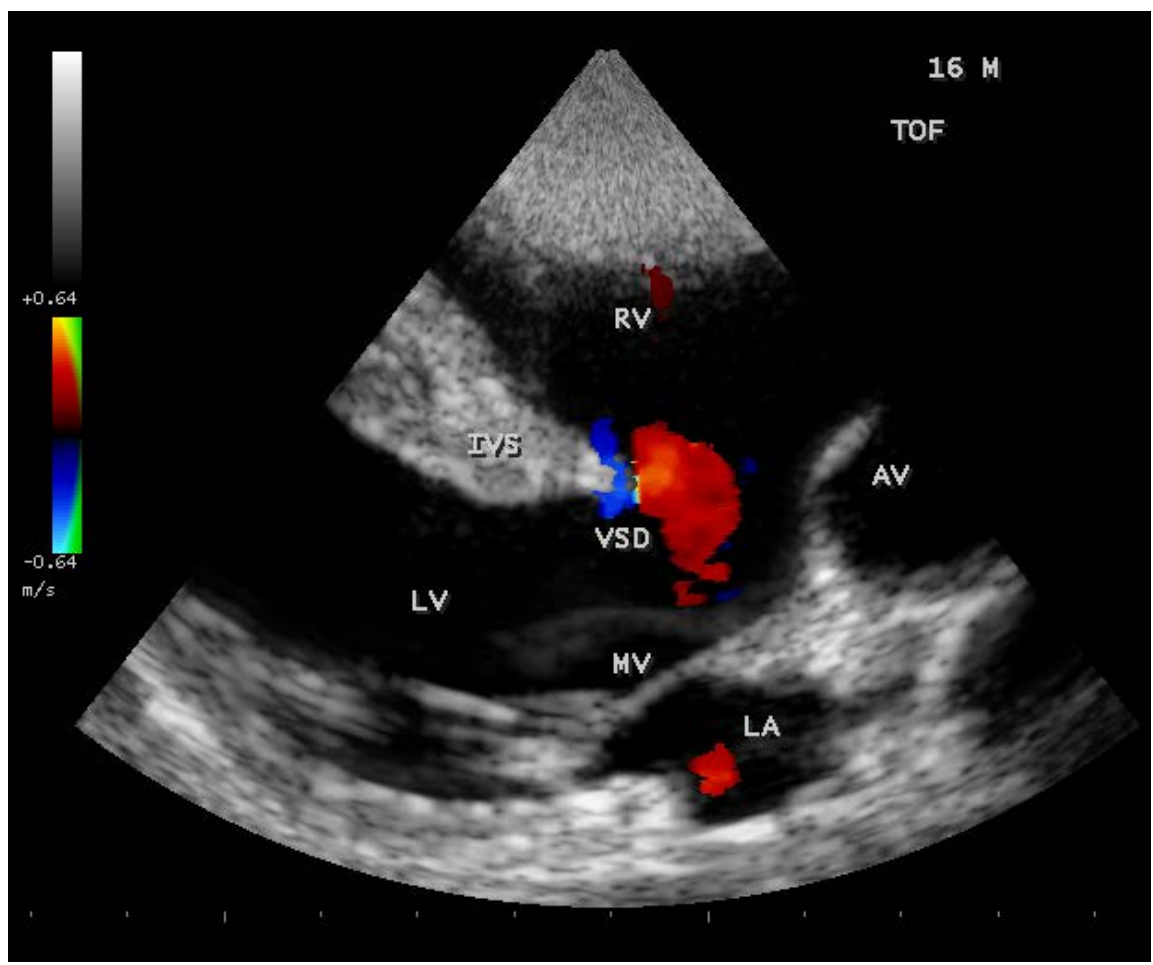

Figure 2. Showing the large, malaligned VSD (ventricular septal defect) of Tetralogy of Fallot in a 16-year old boy. 


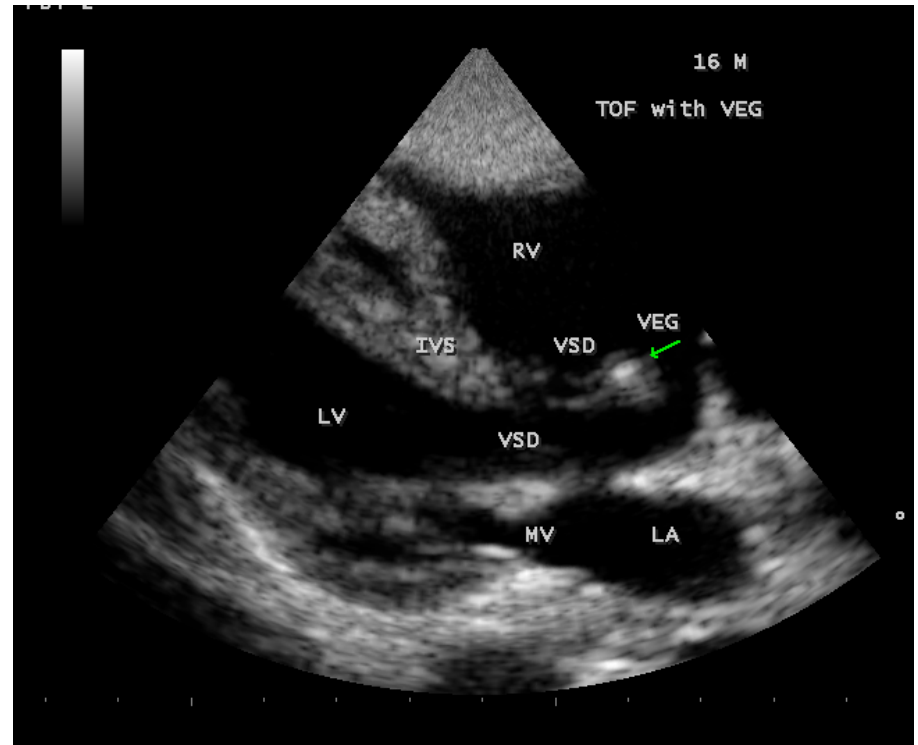

Figure 3. Showing "the vegetation" (arrow) attached to the crest of IVS (interventricular septum) in a 16-year old boy with Tetralogy of Fallot.

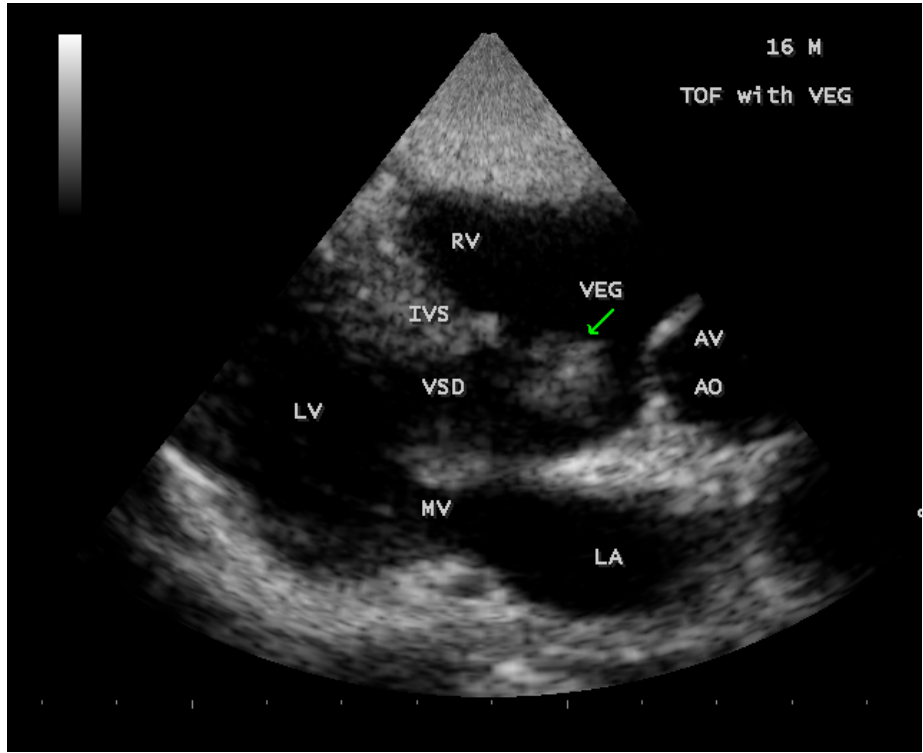

Figure 4. Showing "the vegetation" (arrow) seen across the VSD (ventricular septal defect) in a 16-year old boy with Tetralogy of Fallot.

\section{Discussion}

\section{Review of Literature}

Rushani and colleagues found that $34 \%$ of children with infective endocarditis had cyanotic CHD [8]. Elder and Baltimore found that infective endocarditis represented 0.05 to 0.12 per 1000 pediatric admissions. Tetralogy of Fallot (TOF) was described in 1888 by the French physician Etienne-Louis Arthur Fallot [9]. In 1814, Farre [10] discussed a case of tetralogy of Fallot in a boy aged 9 years who died of brain abscess. Lallemand Louis and Berthody [11] described similar cases and in 1880, Ballet reviewed the literature of it. Abbott and her collabora- 
tors [12] reported two cases in 1923 and Rabinowitz and associates [13] were the first to report a case with correct antemortem diagnosis in 1932. Wechsler and Kaplan [14] described two cases in 1940.

\section{Etiopathogenesis}

TOF accounts for $10 \%$ of all cases of congenital heart disease [15] and the incidence of brain abscess in population with congenital heart disease varies from $5 \%$ to $18.7 \%$ [16]. In Fallot's tetrad, Bing and associates [17] have shown that the shunting from right-to-left occurs in the absence of failure, owing to the overriding of aorta. When a reversal of flow is said to occur, favouring paradoxical embolism and paradoxical brain abscess stands second only to bacterial endocarditis.

Acute infective endocarditis is a tumultuous, destructive infection frequently involving a highly virulent organism such as staphylococcus or pseudomonas. Staphylococcus aureus is pervasive, with fibronectin binding protein on its surface. When integrins are exposed, they provide adhesion for circulating staphylococci which may also infect normal undamaged endocardium and once adherent, staphylococcus aureus internalizes and escapes host defences. Subacute infective endocarditis is "benign" with a typically more indolent course, often more than 6 weeks, and usually involves a less virulent organism such as streptococci infecting an anatomically damaged heart. Some viridans group streptococci have a type 1 fimbrial subunit that is a major adhesive protein to fibrin platelet aggregates.

Pulmonary circulation represents a potential filtering apparatus for systemic bacterial pathogens. In patients with right-to-left shunts, absence of pulmonary phagocytic clearance of pathogens can occur and the ischemic injury from hypoxaemia and polycythaemia, produce low perfusion areas (microinfarcts) in the brain which may act as a nidus for infection [18]. In the development of brain abscess, inoculation of an organism is required into the brain parenchyma in an area of devitalized brain tissue or in a region with poor microcirculation and the seeded microorganisms can sustain growth and multiply to form abscess. Altered blood brain barrier permeability can occurs and infections from any systemic source may lead to bacteremia and subsequent spread to brain parenchyma even in the absence of cyanotic heart disease.

Brain abscess begins with a localized area of inflammatory change referred to as cerebritis. This early stage of infection is characterized by increased blood vessel permeability without angiogenesis. When unrecognized, this process will progress to an immature capsular stage and then to brain abscess, a condition defined by an area of parenchymal infection containing pus encapsulated by a vascularized membrane. Histologically, there are four stages in brain abscess formation: early cerebritis (day 1 - 3), late cerebritis (day 4 - 9), early encapsulation (day 10 - 13) and late capsule stage (>14 days) [19]. About 2 weeks are required for encapsulation, which is usually less complete on medial or ventricular side due to poor vascular supply [20]. The brain abscess capsule serve to prevent the infective process from becoming generalized and it also creates within it an 
inflammatory "soup" that may impede resolution of the infection.

The mode of entry of organism could be by contiguous (primary dental, sinus, ear infections, or mastoiditis) spread ( $14 \%$ to $58 \%$ ), hematogenous (endocarditis, pulmonary infections such as pneumonia, empyema and abscess) dissemination (9\% to 43\%) from a distant site as investigated by Warrington in 1918 [21] or following trauma and invasive neurosurgical procedures (3\% to $18 \%$ ). The incidence of brain abscesses is about $8 \%$ of intracranial masses in developing countries, whereas, in Western countries, the incidence is about $1 \%-2 \%$ [22]. The predisposing factors of brain abscess are shown in Table 1.

Several predisposing factors are casually related, but in $14 \%-25 \%$ of patients, no cause can be found [25] [26].

A single organism is isolated in majority of bacterial brain abscess. Anaerobic streptococci are most common agents in cyanotic heart disease with brain abscess. However, isolation of multiple pathogens from abscess materials is not uncommon (4\% - 23\%) [27] [28]. Cultures are negative in 16-68\% of brain abscess with cyanotic heart disease [29]. Administration of antibiotics prior to the collection of abscess material is often cited as the explanation for sterile culture. The abscess drained within 3 days of antibiotic administration had much greater yield than otherwise ( $84 \%$ and $32 \%$ respectively) [30]. Bacteroides fragilis and peptostreptococcus are the most common anaerobic organisms isolated [31]. Organisms vary significantly with the etiology of abscess as shown in Table 2 [32].

Individuals with AIDS having brain abscess are more likely to have multiple abscesses and tuberculous abscess. Toxoplasma encephalitis is the most common multifocal infectious process encountered in advanced HIV and this population is more susceptible to intracranial infections from Listeria, Cryptococcus, and Nocardia [33].

Fungal brain abscess mostly related to Aspergillus and other species including candida are common in organ transplant patients and immunocompromise raises the risk of CNS infection with an incidence as high as $37.5 \%$.

Moyamoya disease, a vaso-occlusive disease of cerebral blood vessels with a number of collaterals at the base of brain giving a "smoke of puff" ("moyamoya" in Japanese) is rarely associated with TOF and presents with CNS involvement such as stroke and seizures [34] and may produce abscess in the brain.

Abscess can occur in any location of brain, which is closely associated with source [35]. Otogenic abscess occurs almost exclusively in the temporal lobe and

Table 1. Showing the predisposing factors of brain abscess.

Congenital heart disease with a right-to-left shunt [23]

Infections of middle ear, mastoid, paranasal sinuses, orbit, face, scalp, penetrating skull injury and comminuted skull fracture

Intracranial surgery including insertion of ventriculo-peritonial shunts

Abnormal immune functions [24] 
Table 2. Showing the varying organisms with the etiology of abscess.

\begin{tabular}{cl}
\hline \multicolumn{1}{c}{ Source } & \multicolumn{1}{c}{ Most commonly cultured organisms } \\
\hline \multirow{3}{*}{ Paranasal sinus infection } & Streptococcus spp. \\
& Staphylococcus spp. \\
& Enterobacteriaceae (especially \\
& Hemophilus spp., Pseudomonas aeruginosa) \\
& Proteus mirabilis \\
Otogenic infection & Streptococcus millerigroup organisms \\
& Streptococcus pneumoniae \\
& Staphylococcus aureus \\
& Streptococcus spp. \\
Dental infection & Bacteroides fragilis \\
& Staphylococcus aureus \\
Traumatic brain injury & Staphylococcus epidermidis \\
& Enterobacteriaceae \\
& (most commonly P. aeruginosa, Enterobacter spp.) \\
& Staphylococcus aureus \\
& Staphylococcus epidermidis \\
Heurosurgical procedure & Pseudomonas aeruginosa \\
& Propionibacterium acnes \\
& Streptococcus spp. \\
& Staphylococcus aureus \\
& Streptococcus viridans \\
& Klebsiella pneumoniae \\
& \\
&
\end{tabular}

cerebellum [36], while abscess associated with sinus infection is predominantly frontal [37] [38]. A significant proportion of individuals develop multiple abscesses (9.3\% - 28\%) [39] [40] [41].

\section{Echocardiographic Features}

The four components of TOF are ventricular septal defect (VSD), aortic override, right ventricular outflow tract obstruction and right ventricular hypertrophy. In unrepaired TOF, pathophysiology depends on the degree of RVOT obstruction. When obstruction of right ventricular outflow is mild to moderate and a fairly balanced shunt operates across VSD and the patient may not be cyanotic, called as "acyanotic" or "pink" tetralogy of Fallot. The patient may remain relatively asymptomatic until the balance between pulmonary and systemic circulation is disturbed.

Echocardiography plays a key role in the diagnosis of infective endocarditis (IE) in TOF. Vegetation may occur on pulmonary and tricuspid valves [42] and a large vegetation occluding the VSD had been reported [43]. In this patient, a large vegetation attached to the crest of interventricular septum was shown in Figure 3 and Figure 4.

\section{CT Imaging}

Brain abscess is an encapsulated inflammation and can be easily diagnosed by CT scan. The CT appearance of an abscess is that of a well defined hypodense area showing ring enhancement and accompanied by extensive perifocal edema and mass effect. The ring enhancement on the CT scan surrounding a central 
necrotic cavity as in Figure 5 is an abscess. The appearance of enhancing rim, the capsule of the abscess enhances and it is variable. The rim is formed probably by collagen and inflammation due to free radicals and micro hemorrhages in the abscess. The abscess tends to grow towards white matter, away from the better vascularized grey matter, with thinning of the medial wall. The preferential deposits of collagen on the outer edge of the abscess are due to the vascularization of grey matter. The zone of inflammation is significantly thicker in tuberculous as compared to pyogenic abscess. The neuroimaging features of brain abscess vary with lesion stage as shown in Table 3. During the cerebritis stage (local suppurative encephalitis or immature abscess), ring enhancement may be absent or incomplete. Abscesses with a more nodular rim are often mistaken for neoplasm. Brain abscesses tend to have a smooth, thin walled capsule and it is more irregular in tumors. In contrast to tumor, the abscess rim is typically thicker near the cortex and thinnest near the ependyma. Early capsule stage is characterized by formation of a distinct collagenous capsule, which is well delineated, relatively thin, uniform and continuous. The uniformely enhancing capsule is typical of a mature abscess. The abscess gradually shrink, peripheral edema diminishes and then disappears in the late capsule stage.

The apparent budding of smaller, "daughter" lesion from the main mass is called as "daughter abscess". In about $50 \%$ of cases, the medial wall of an abscess is thinner than the lateral one and is thought to be due to the relatively poor vascular supply of the white matter. This explains the tendency of abscess to rupture into the ventricles and the development of secondary abscesses (daughter abscess) medially [45] may be seen near the primary lesion as in Figure 6 and Figure 7. In deep seated, multiloculated and periventricular abscesses, a reduction of $1 \mathrm{~mm}$ in the distance between the ventricle and brain abscess wall increases the rupture rate by $10 \%$ [46]. Smooth, $<5 \mathrm{~mm}$ thick with medial thinning helps in differentiating an abscess from a cystic tumor and a finding of gas within

Table 3. The CT features of brain abscess according to the stages of development.

\begin{tabular}{ll}
\hline \multicolumn{1}{c}{ Stages } & \multicolumn{1}{c}{ CT appearance } \\
\hline Marly cerebritis & $\begin{array}{l}\text { Poorly marginated cortical or subcortical hypodensity with mass } \\
\text { effect with little or absence of enhancement. } \\
\text { An ill-defined area of low density on plain CT corresponds } \\
\text { to developing necrotic center in the cerebritis stage. }\end{array}$ \\
Late cerebritis & $\begin{array}{l}\text { Irregular ring-enhancing lesion with a } \\
\text { hypodense center, better defined than early cerebritis. }\end{array}$ \\
& Well-defined rim-enhancing mass, an outer hypodense and inner \\
hyperdense rim (double rim sign) is seen in most cases. \\
A slightly hyperdense, faint ring is seen surrounding a necrotic \\
hypodense center [44]. \\
Rim-enhancing lesion with thickened capsule and diminished \\
hypodense central cavity. \\
The capsule is seen as a ring in plain CT.
\end{tabular}




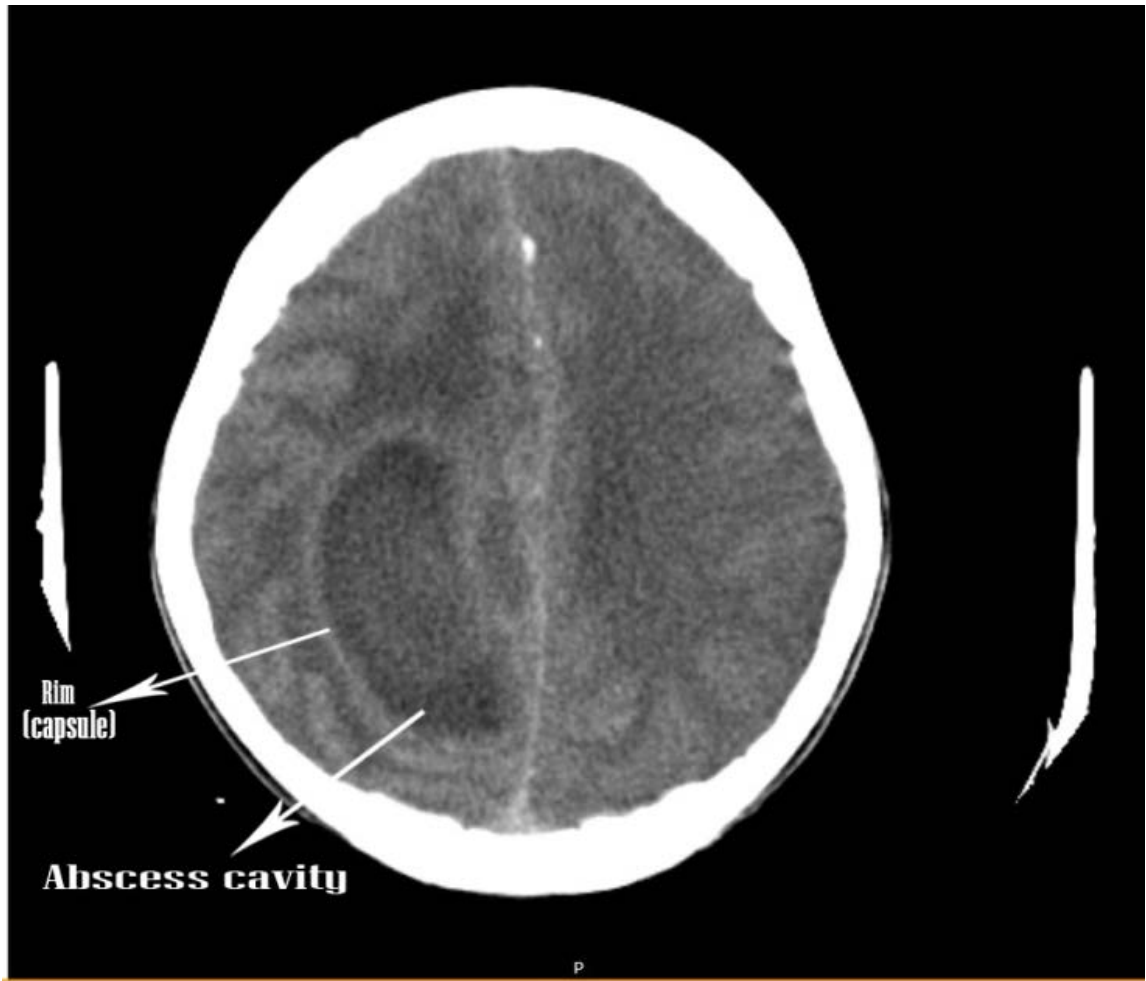

Figure 5. CT brain showing the large abscess cavity in the parietal lobe with mild midline shift in a 16-year old boy with Tetralogy of Fallot. Upper arrow showing the Rim (capsule) and the lower arrow showing the abscess cavity.

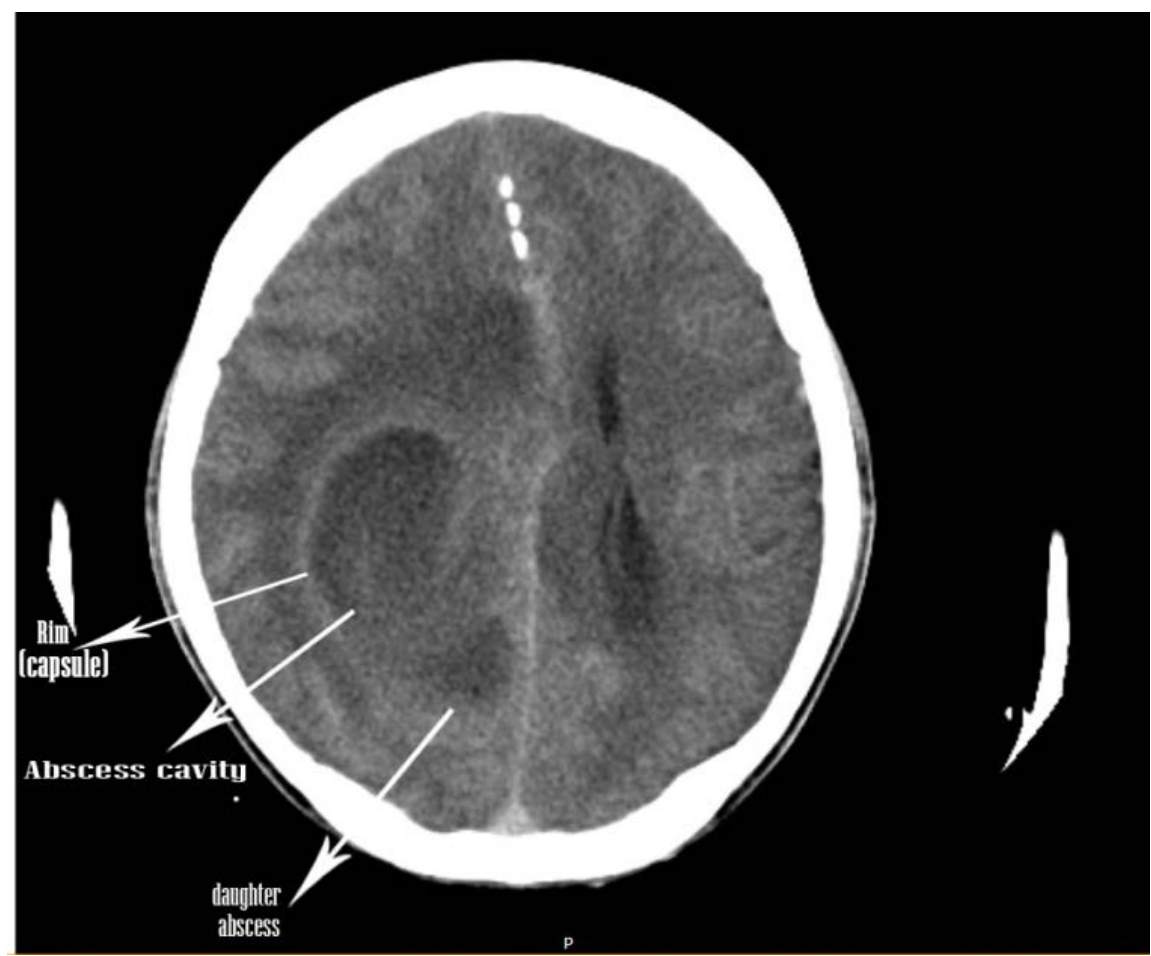

Figure 6. CT brain showing the large abscess cavity in the parietal lobe with "daughter abscess" in the lower part (lowest arrow) with moderate midline shift in a 16-year old boy with Tetralogy of Fallot. 


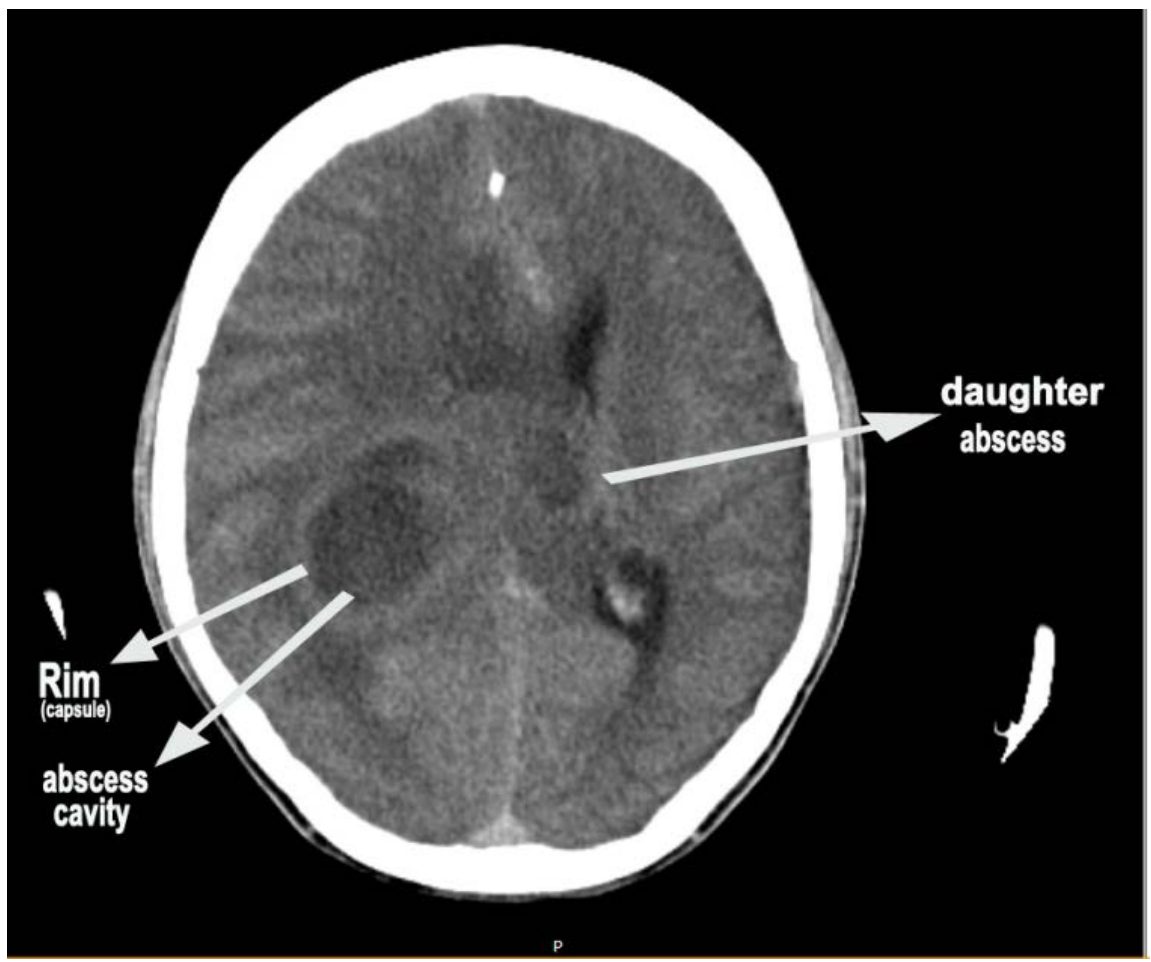

Figure 7. CT brain showing the large abscess cavity in the parietal lobe with small "daughter abscess" in the upper part (right arrow) in a 16-year old boy with Tetralogy of Fallot.

the lesion favor a diagnosis of an abscess. Unfortunately, brain abscess may spontaneously bleed, presenting as an intracerebral hemorrhage [47].

As reported by Landriel et al. [48], brain abscesses were solitary in $77.7 \%$ of the subjects and multiple (22.3\%) abscesses are more common in immunocompromised children and infective endocarditis [49]. The temporoparietal region was the most commonly affected location in a study carried out by Cavusoglu et al. [50]. In children, the most common location was in the parietal region (55\%), frontal (28\%), temporal (13\%) and occipital (4\%). The location of brain abscess as stated by Brook [51] was frontal lobe (47.1\%), parietal (29.4\%), temporal (13.7\%) and occipital (9.8\%).

MRI has also proven to detect small, multiple abscesses and may render superior images of posterior fossa location and more sensitive to distinguish cerebritis from necrosis [52], but not better than CT in distinguishing abscesses from neoplasms and the diffusion-weighted imaging can aid in this distinction [53] as hypointense abscess capsule on T2-weighted sequence may allow for this differentiation and the surrounding edema is apparent whereas in T1-weighted image, the capsule enhances and the interior of the abscess is hypointense. In T2-weighted images, the wall of the abscess is dark and it is bright in neoplasms.

MRS (Magnetic resonance spectroscopy) appears to be useful in the diagnosis of abscesses arising from anaerobic infections because these species produce lactate and acetate, which are readily apparent on MRS and rarely found within tumor tissue [54]. 
Practically, all abscesses $>1 \mathrm{~cm}$ produce positive scans. Thus, CT scan appears to be adequate in most cases of brain abscess, but in very small miliary abscesses and brain stem abscess in which MRI with specialized sequence or MRS is indicated.

\section{Management}

The first reference to brain abscess is attributed to Hippocrates in the fifth century B.C [55]. Sir Williams MacEwen was called as the "father" of modern brain abscess management for the publication of his famous monograph Pyogenic Infective Diseases of the Brain and Spinal cord in 1893. The treatment of brain abscess has been a challenge. The basic principle of treatment is the selection of appropriate antibiotics with or without aspiration.

\section{Medical Therapy}

Small brain abscesses have been treated empirically with antibiotics [56]. Heineman and colleagues became the first to report the successful medical management of a brain abscess in 1971 [57]. Medical therapy alone can be considered in patients with a lesion in the cerebritis stage since they are much more likely to respond to antibiotic therapy because of lack of a capsule [58] and also for walled off, but $<2$ to $3 \mathrm{~cm}$ in diameter abscess [59] or surgically inaccessible abscesses such as brain stem abscesses [60]. The first report of an encapsulated abscess cured by medical therapy alone was published by Chow et al. in 1975 [61]. Rosenblum, Mampalam and Pons recommended that nonoperative treatment of brain abscess should be reserved for abscess $<1.5 \mathrm{~cm}$ or for patients with uncontrollable bleeding diathesis

The complexity of microbial flora in brain abscess necessitates empirical antibiotic therapy against both aerobic and anaerobic organisms. Usually, intravenous administration of "triple high dose" antibiotics $\left(3^{\text {rd }}\right.$ generation cephalosporin + vancomycin and metronidazole) for 2 weeks followed by 4 weeks of oral therapy is recommended. The third generation cephalosporins have good central nervous system penetration and excellent in vitro activity against many pathogens isolated from bacterial brain abscess. Metronidazole is highly active against anaerobic bacteria, including Bacteroides fragilis, the most resistant anaerobe. Metronidazole readily penetrates brain abscess, intralesional concentration have been found to be $40 \mu \mathrm{g} / \mathrm{ml}$ and attains high concentration in the pus [62]. Therefore, metronidazole is usually combined with third generation cephalosporin (cefotaxime or ceftriaxone) or penicillin $G$ for the treatment of cyanotic brain abscess [63], but is not active against aerobic organisms including microaerophilic streptococci and the duration of treatment is usually 4 - 6 weeks [64].

Sulfa drugs are most effective in Nocardia abscess and vancomycin against staphylococcus. Neurotoxicity such as seizures have been reported with imepenem [65] and meropenem should be preferred for abscess due to multidrug-resistent Enterobacter cloacae [66] and successful outcome has been reported. Quinolones can lower seizure thresholds [67] and should be used with caution in the treatment of cerebral abscess.

In immunocompromised patients, empirical therapy should be avoided since 
they are more prone for infection with intracellular pathogens such as fungi (aspergillus) and bacteria like Nocardia or infection with human immunodeficiency virus, emphasizing the need for specific microbiological diagnosis as biopsy of the lesion may reveal a tuberculoma, which responded to antituberculous drugs [68].

\section{Hyperbaric Oxygen Therapy $\left(\mathrm{HBO}_{2}\right.$ or HBOT)}

It is indicated as a primary and adjunct treatment to reduce intracranial pressure and high partial pressure of oxygen act as a bactericide and thus inhibit the anaerobic flora common in brain abscess. It optimizes the immune function, enhancing the host defence mechanisms and it has been found to be of benefit when brain abscess is concomitant with cranial osteomyelitis. It also increases the stem cell production and up-regulation of VEGF which aid in the healing and recovery process [69].

\section{Antiinflammatory Agents}

The glial cell activation in brain abscess is through parenchymal microglia and astrocytes. Activated microglia has the potential to influence the type and extent of antibacterial adaptive immune response through upregulation of $\mathrm{MHC}$ class II and costimulatory molecule expression. The control release of proinflammatory mediators may damage the surrounding brain parenchyma [70] and the cytokines IL- 1 and TNF- $\alpha$ establish an effective antibacterial response in the CNS parenchyma. Recent studies support persistent immune activation in brain abscess with elevated levels of IL-1, TNF- $\alpha$ and macrophage inflammatory protein-2 (MIP-2), detected 14 to 21 days following staphylococcus aureus exposure.

Interventions with anti-inflammatory agents subsequent to sufficient bacterial neutralization may be an effective strategy to minimize the damage in the surrounding brain parenchyma during the course of brain abscess development, leading to improvements in cognition and neurological outcome [71].

However, if coagulation abnormalities are present, especially in cyanotic CHD, nonsteroidal anti-inflammatory drugs should be avoided, platelet concentrate needs to be available perioperatively [72] and when the hematocrit $>65 \%$ requires phlebotomy and adequate hydration to maintain intravascular volume.

\section{Role of Steroids}

Corticosteroids play a role as an adjunctive therapy to control cerebral edema in patients with potentially life-threatening complications such as impending cerebral herniation. Corticosteroids are used when a significant mass effect is visible on imaging and the patient's mental status is depressed, but had some adverse effects to retard the encapsulation process [73] [74], increase necrosis, reduce antibiotic penetration (polar antibiotics such as benzylpenicillin) into the abscess, increase the risk of ventricular rupture, and decrease the enhancement of abscess wall on CT due to contrast reduction as inflammation subsides [75]. The tissue concentrations of more lipophilic substances, such as metronidazole, were not affected by concomitant corticosteroid therapy [76] and it should be the part of antibiotic regimen. The corticosteroid of choice for reducing the in- 
tracranial pressure is dexamethasone and it may decrease inflammation by suppressing the migration of polymorphonuclear leukocytes and reversing increased capillary permeability. When used to reduce the cerebral edema, therapy should be of short duration and high-dose corticosteroid therapy (IV dexamethasone 8 mg every 8 hours) should be given and then tapered off after the patient's condition has stabilized. Even though retrospective studies failed to show a beneficial effect of corticosteroids on outcome [77] [78], however, corticosteroids are given mostly to severely obtunded and comatose patients who are known to have a dismal prognosis [79] [80]. Severe brain abscess may necessitate further measures to reduce the increased intracranial pressure, such as osmotherapy (e.g. mannitol) and hyperventilation. Even though mannitol helps to decrease intracranial pressure, cerebral edema and ideal to reduce blood viscosity, it can cause severe dehydration, hypotension, tachycardia, acidosis and precipitate "tet spell".

\section{Surgical Therapy}

Surgery is the treatment of choice for most brain abscess to confirm the diagnosis, allow direct identification of the causative organism, and to decompress the abscess cavity. A number of surgical techniques have been developed to treat brain abscess over the last two centuries, range from the tube drainage methods of the past to modern computer-guided minimally invasive approaches for abscesses $<1.5 \mathrm{~cm}$ accurately with minimal morbidity. The first successful operation for brain abscess was performed by French surgeon S. F. Morand in 1752 on a temperoethmoidal abscess [81]. King introduced marsupialization in 1924 [82] and Dandy introduced aspiration in 1926 [83]. Sargeant considered the procedure of enucleation of an encapsulated brain abscess in 1928 [84] and Vincent popularized complete excision and proved its value in 1936.

Surgical drainage provides the most optimal therapy and the procedures used are aspiration through a burr-hole and complete excision after craniotomy. Needle aspiration is preferred and the most commonly used technique, often performed using a stereotactic procedure with a guidance of ultrasound or CT scanning [85], especially for deep-seated abscesses (brainstem, cerebellum and basal ganglia). Often, external drainage of the abscess through an intra-cavity catheter is recommended for abscesses $>3 \mathrm{~cm}$ in diameter. Total excision is preferred for solitary, superficial and encapsulated abscesses. Abscess containing gas are resistant to antibiotics and are better treated with excision [86]. Brain abscess caused by Nocardia asteroids are multiloculated and excision must be performed to effect a cure [87] and may not be successfully treated by aspiration. Excision is also reserved for abscesses that enlarge after 2 weeks of antibiotic therapy or that fail to shrink after 3 - 4 weeks of antibiotics because of adhesions to the dura and also for posterior fossa abscesses, especially in the cerebellum, which may compress CSF pathways and thereby lead to dangerously high intracranial pressure and carry a mortality rate of $20 \%$ to $50 \%$ [88]. The current recommendations are to drain these abscesses through a posterior fossa craniotomy and to perform CSF diversion through an external ventricular drain in patients with any radiologic signs of hydrocephalus. Excision should not be considered for abscesses in 
the cerebritis stage, deep-seated abscesses in the eloquent areas and multiple abscesses.

The "migration technique" described by Khan in 1937 [89] is a two-stage technique that included a decompressive craniotomy followed by a second procedure 3 to 4 days later for either excision or drainage of the abscess. He noted that when a craniotomy was performed for the relief of increased intracranial pressure, brain abscess tended to migrate toward the cranial opening.

Neuroendoscopic technique with freehand stereotaxy has also been practiced [90] and it has an additional advantage of more complete drainage and lavage, when compared to stereotactic aspiration [91].

It is suggested that irrigation of abscess cavity with antibiotic solution raises antibiotic levels and reduces the bacterial load, allowing the infectious process to resolve more quickly [92]. However, local administration of antibiotics is not routinely recommended because intravenous antibiotics used for brain abscess treatment penetrate the brain and abscess capsule, achieving therapeutic intacavitary levels [93]. Antibiotic irrigation may prove helpful in case of rupture of a brain abscess into the ventricle [94].

\section{Five Component Therapy}

The encapsulation of a brain abscess often is more complete on the cortical than on the ventricular side. Thus, it is more likely to rupture into the ventricles rather than laterally into the subarachnoid space. The intraventricular rupture of brain abscess (IVOBRA) results in severe headache, an increase of meningeal irritation, a rapidly deteriorating clinical condition, and an enhancement of the ventricular wall adjacent to the abscess often preceded IVOBRA [95]. Most authors proposed an aggressive approach with regard to its clinical prognosis. Zeidman, Geisler, and Olivi have proposed a five-component therapeutic plan [96], consisting of open craniotomy with debridement of the abscess cavity, lavage of the ventricular system, ventricular drainage, intrathecal gentamycin, and intravenous administration of appropriate antibiotics. However, the role of intrathecal antibiotics is disputed [97].

Seizure is a long term risk for up to $30 \%-50 \%$ of patients suffering from brain abscess [98]. The hypo-dense areas surrounding the abscess cavity are thought to cause epileptic activity and it is mainly related to scars after excision rather than with aspiration. Antiepileptic medication was advised in all cases and continued for at least 2 years and then slowly withdrawn when the EEG remains normal and the patient is seizure free for at least 2 years after surgery. Legg advocated anticonvulsant therapy for 5 years to all patients with cerebral abscess [99]. Seizures are initial presentation of brain abscess up to $35 \%$ of cases and should be controlled with intravenous benzodiazepines such as lorazepam or midazolam or fosphenytoin. For the prevention of further seizures, carbamazepine is recommended, in addition to phenytoin.

The risk of recurrence is $10 \%-50 \%$. To prevent recurrence of the abscess, the source of infection should be treated surgically or medically [100]. Correction of 
cardiac anomaly is necessary to prevent recurrent brain abscess in cyanotic CHD.

\section{Case Analysis}

The primary source of infection in this case is vegetative lesion in the heart, which in turn leads to hematogenous dissemination to brain, resulting in abscess formation, when the filtering effect of lungs, the current theory of mechanism, is circumvented in Tetralogy of Fallot and the abscess is usually solitary in children. The boy was afebrile since the fever is characteristic of early invasive phase of cerebritis and may return to normal similarly with leukocytosis when the abscess was encapsulated. The size of an abscess may not change for $>2$ weeks after the institution of successful medical therapy [101] and it may needs 10 weeks before the abscess resolved on CT scanning. The ineffectiveness of antibiotics in the stage of capsule formation is due to the acidic medium within the abscess cavity and the inability to have adequate therapeutic concentration of antibiotics within the abscess. Therefore, surgical treatment is essential once the abscess is encapsulated [102]. Stereotactic aspiration is appropriate for abscesses located in the eloquent regions of the brain because it provides a direct and rapid access to the abscess through a predetermined route. Penetration of a thick abscess wall with a blunt-tipped stereotactic probe can be difficult and so freehand aspiration technique was preferred in this case.

\section{Outcome}

Long term outcome in children included complete recovery (30\%), hemiparesis (37\%) and seizure disorder (16\%) [103]. According to four recent studies, the mortality rate of brain abscess was $13 \%(6 \%$ - 24\%) [104], which had decreased substantially after the introduction of CT scanning.

\section{Conclusion}

Brain abscess associated with cyanotic CHD, when presented with rapidly progressive neurological deficit due to mass effect is an indication for urgent decompression. The resolution of surrounding edema and enhancing rim may take up to 6 months and the abnormal enhancement on CT can persists for years after the successful treatment of abscess due to mild breakdown of blood-brain barrier, but not due to residual infection [105] [106].

\section{Conflicts of Interest}

The author declares no conflicts of interest regarding the publication of this paper.

\section{References}

[1] Ranjith, K.M. and Vedantam, R. (2008) Management of Brain Abscess: An Overview. Neurosurgical Focus, 24, 1-6. https://doi.org/10.3171/FOC/2008/24/6/E1

[2] Atiq, M., Ahmed, U.S., Allana, S.S. and Chishti, K.N. (2006) Brain Anscess in Children. Indian Journal of Pediatrics, 73, 401-404. 
https://doi.org/10.1007/BF02758560

[3] Raha, A., Ganjoo, P., Singh, A., Tandon, M.S. and Singh, D. (2012) Surgery For Brain Abscess in Children with Cyanotic Heart Disease. An Anaesthetic Challenge. Journal of Pediatric Neurosciences, 7, 23-26. https://doi.org/10.4103/1817-1745.97617

[4] Kagawa, M., Takeshita, M., Yato, S., et al. (1983) Brain Abscess in Congenital Cyanotic Heart Disease. Journal of Neurosurgery, 58, 913-917. https://doi.org/10.3171/jns.1983.58.6.0913

[5] Chakraborty, R.N., Bidwai, P.S., Kak, V.K., et al. (1989) Brain Abscess in Cyanotic Congenital Heart Disease. Indian Journal of Pediatrics, 41, 190-193.

[6] Moorthy, R.K. and Rajshekhar, V. (2008) Management of Brain Abscess: An Overview. Neurosurgical Focus, 24, E3. https://doi.org/10.3171/FOC/2008/24/6/E3

[7] Prusty, G.K. (1993) Brain Abscesses in Cyanotic Heart Disease. Indian Journal of Pediatrics, 60, 43-53. https://doi.org/10.1007/BF02860506

[8] Leonard, E.J., Kuebler, B.E., Zenni, M.M. and Scuderi, C.B. (2017) A Review of Infective Endocarditis Associated with Congenital Heart Disease. Consultant, 57, 636-641.

[9] Hepburn, L. (2011) Tetralogy of Fallot. Anaesthesia Tutorial of the Week, 219.

[10] Farre, J.R. (1814) On Malformations of the Human Heart. Longmans, London, 24.

[11] Berthody, C. (1845) Case of Communication between the Ventricles of the Heart, the Aorta Originating from both Ventricles. The Medical Examiner, Philadelphia, 261.

[12] Abbott, M.E. (1926) On the Incidence of Bacterial Inflammatory Processes in Cardiovascular Defects and on Malformed Semilunar Cusps. Annals of Clinical Medicine, 4, 189.

[13] Rabinowitz, M.D., Weinstein, J. and Marcus, I.H. (1932) Brain Abscess (Paradoxical) in Congenital Heart Disease. American Heart Journal, 7, 790. https://doi.org/10.1016/S0002-8703(32)90440-2

[14] Wechsler, L.S. and Kaplan, A. (1940) Cerebral Abscess (Paradoxic) Accompanying Congenital Heart Disease. Archives of Internal Medicine, 66, 1282. https://doi.org/10.1001/archinte.1940.00190180094007

[15] Hamid, M., Khan, M.A., Akhtar, M., Hameedullah, S., Samad, K., et al. (2010) Grown up Congenital Heart Disease Patient Presenting for Non Cardiac Surgery: Anaesthetic Implications. Journal of the Pakistan Medical Association, 60, 955-959.

[16] Monco, J.C.G., Beldarrain, M.G., Canton, G.F., et al. (1997) Resolution of a Brainstem Abscess through Antituberculous Therapy. Neurology, 49, 265-267. https://doi.org/10.1212/WNL.49.1.265

[17] Bing, R.J., Vandom, L.D. and Gray, F.D. (1947) Physiological Studies in Patients with Congenital Heart Disease, II. Results of Preoperative Studies in Patients with Tetralogy of Fallot. Bulletin of the Johns Hopkins Hospital, 80, 121.

[18] Lumbiganon, P. and Chaikitpinyo, A. (2013) Antibiotics for Brain Abscess in People with Cyanotic Congenital Heart Disease. The Cochrane Database of Systematic Reviews, 3, CD004469. https://doi.org/10.1002/14651858.CD004469.pub3

[19] Ersin, E. and Tufan, C. (2008) Pyogenic Brain Abscess. Neurosurgical Focus, 24, 1-10. https://doi.org/10.3171/FOC/2008/24/6/E1

[20] Britt, R.H. (1985) Brain Abscess. In: Wilkins, R.H. and Rengachary, S.S., Eds., Neurosurgery, McGraw-Hill, New York, 1928-1956.

[21] Warrington, W.B. (1918) Abscess of The Brain. The Quarterly Journal of Medicine, 
2, 141-164. https://doi.org/10.1093/qjmed/os-11.42.141

[22] Zhang, C., Hu., L., Wu., X., Hu., G., Ding, X. and Lu, Y. (2014) A Retrospective Study on the Etiology, Management, and Outcome of Brain Abscess in an 11-Year, Single-Centre Study from China. BMC Infectious Diseases, 14, 311. https://doi.org/10.1186/1471-2334-14-311

[23] Takeshita, M., Kagawa, M., Yonetani, H., Izawa, M., Yato, S., Nakanishi, T. and Monma, K. (1992) Risk Factors for Brain Abscess in Patients with Congenital Cyanotic Heart Disease. Neurologia Medico-Chirurgica, 32, 667-670. https://doi.org/10.2176/nmc.32.667

[24] Parikh, S., Bharucha, B. Kamdar, S. and Kshirsagar, N. (1993) Polymorphonuclear Leukocyte Functions in Children with Cyanotic and Acyanotic Heart Disease. Indian Pediatrics, 10, 883-890.

[25] Aebi, C., Kauffmann, F. and Schaad, U.B. (1991) Brain Abscess in Childhood-Long Term Experience. European Journal of Pediatrics, 150, 282-286. https://doi.org/10.1007/BF01955533

[26] Pit, S., Jamal, F. and Cheak, F.K. (1993) Microbiology of Cerebral Abscess: A Four Year Study in Malaysia. The Journal of Tropical Medicine and Hygiene, 96, 191-196.

[27] Sarmast, A.H., Showkat, H.I., Bhat, A.R., et al. (2012) Analysis and Management of Brain Abscess, a Ten Year Hospital Based Study. Turkish Neurosurgery, 22, 682-689. https://doi.org/10.5137/1019-5149.JTN.5458-11.3

[28] Radoi, M., Ciubotaru, V. and Tataranu, L. (2013) Brain Abscess: Clinical Experience and Outcome of 52 Consecutive Cases. Chirurgia, 108, 215-225.

[29] Takeshita, M., Kagama, M., Yato, S., Izawa, M., Onda, H., Takakura, K., et al. (1997) Current Treatment of Brain Abscess in Patients with Congenital Cyanotic Heart Disease. Neurosurgery, 41, 1270-1279. https://doi.org/10.1097/00006123-199712000-00006

[30] Roche, M., Humphreys, H., Smyth, E., et al. (2003) A Twelve-Year Review of Central Nervous System Bacterial Abscess. Presentation and Etiology. Clinical Microbiology and Infection, 9, 803-809. https://doi.org/10.1046/j.1469-0691.2003.00651.x

[31] Menon, S., Bhavadwaj, R., Chowdhary, A., Kaundinya, D.V. and Palande, D.A. (2008) Current Epidemiology of Intracranial Abscesses: A Prospective 5 Year Study. Journal of Medical Microbiology, 57, 1259-1268. https://doi.org/10.1099/jmm.0.47814-0

[32] Patel, K. and Clifford, D.B. (2014) Bacterial Brain Abscess. Neurohospitalist, 4, 196-204. https://doi.org/10.1177/1941874414540684

[33] Cunha, B.A. (2011) Central Nervous System Infections in the Compromised Host: A Diagnostic Approach. Infectious Disease Clinics of North America, 15, 567-590. https://doi.org/10.1016/S0891-5520(05)70160-4

[34] Shambhavi, U. and Sitaraman, S. (2017) Moyamoya Disease as a Cause of Stroke in a Child with Tetralogy of Fallot. Journal of Neurosciences in Rural Practice, 8, 303-304. https://doi.org/10.4103/jnrp.jnrp_308_16

[35] Manzar, N., Manzar, B., Kumar, R. and Bari, M.E. (2011) The Study of Etiologic and Demographic Characteristics of Intracranial Brain Abscess: A Consecutive Case Series Study from Pakistan. World Neurosurgery, 76, 195-200. https://doi.org/10.1016/j.wneu.2011.02.011

[36] Sennaroglu, L. and Sozeri, B. (2000) Otogenic Brain Abscess: Review of 41 Cases. Otolaryngology. Head and Neck Surgery, 123, 751-755.

https://doi.org/10.1067/mhn.2000.107887 
[37] Faraji-Rad, M. and Samini, F. (2007) Clinical Features and Outcome of 83 Adult Patients with Brain Abscess. Archvies of Iranian Medicine, 10, 379-282.

[38] Hakan, T., Erdem, I., Berkman, M.Z. and Goktas, P. (2006) Bacterial Brain Abscess: An Evaluation of 96 Cases. Journal of Infection, 52, 359-366. https://doi.org/10.1016/j.jinf.2005.07.019

[39] Song, L., Guo, F., Zhang, W., et al. (2008) Clinical Features and Outcome Analysis of 90 Cases with Brain Abscess in Central China. Neurological Sciences, 29, 425-430. https://doi.org/10.1007/s10072-008-1019-x

[40] Kao, P.T., Tseng, H.K., Liu, C.P., Su., S.C. and Lee, C.M. (2003) Brain Abscess: Clinical Analysis of 53 Cases. Journal of Microbiology, Immunology and Infection, 36, 129-136.

[41] Carpenter, J., Stapleton, S. and Holliman, R. (2007) Retrospective Analysis of 49 Cases of Brain Abscess and Review of the Literature. European Journal of Clinical Microbiology \& Infectious Diseases, 26, 1-11. https://doi.org/10.1007/s10096-006-0236-6

[42] Hassan, P., Veli, G., Mehmet, N. and Oben, D. (2004) Cyanotic Tetralogy of Fallot with Its Infective Endocarditis Complication on the Tricuspid and Pulmonary Valves of a 55-Year-Old Man. Circulation Journal, 68, 178-180. https://doi.org/10.1253/circj.68.178

[43] Goel, P.K., et al. (2012) Tetralogy of Fallot with Infective Endocarditis: An Echocardiographic Explanation of Misleading Clinical Signs. Pediatric Cardiology, 33, 666-668. https://doi.org/10.1007/s00246-012-0181-3

[44] Sharma, B.S., Gupta, S.K. and Khosla, V.K. (2000) Current Concepts in the Management of Pyogenic Brain Abscess. Neurology India, 48, 105-111.

[45] Stevens, E.A. (1978) CT Brain Scanning in Intraparenchymal Pyogenic Abscesses. American Journal of Roentgenology, 130, 111-114. https://doi.org/10.2214/ajr.130.1.111

[46] Lee, T.H., Chang, W.N., Su, T.M., Chang, H.W., Lui, C.C., Ho, J.T., et al. (2007) Clinical Features and Predictive Factors of Intraventricular Rupture in Patients Who Have Bacterial Brain Abscesses. Journal of Neurology, Neurosurgery, and Psychiatry, 78, 303-309. https://doi.org/10.1136/jnnp.2006.097808

[47] Devi, B., JBhatia, S., Kak, V.K., et al. (1993) Spontaneous Hemorrhage Associated with a Brain Abscess. Child s Nervous System, 9, 481-482. https://doi.org/10.1007/BF00393556

[48] Landriel, F., Ajler, P., Hem, S., Bendersky, D., Goldschmidt, E., Garategui, L., Vecchi, E., Konsol, O. and Carrizo, A. (2012) Supratentorial and Infratentorial Brain Abscess: Surgical Treatment, Complications and Outcome: A 10-Year Single-Center Study. Acta Neurochirurgica, 154, 903-911. https://doi.org/10.1007/s00701-012-1299-Z

[49] Yanagihara, C., Wada, Y. and Nishimura, Y. (2003) Infectious Endocarditis Associated with Subarachnoid Hemorrhage, Subdural Hematoma and Multiple Brain Abscesses. Internal Medicine, 42, 1244-1247. https://doi.org/10.2169/internalmedicine.42.1244

[50] Cavusoglu, H., Kaya, R.A., Turkmenoglu, O.N., Colak, I. and Aydin, Y. (2008) Brain Abscess: Analysis of Results in a Series of 57 Patients with a Combined Surgical and Medical Approach during an 11-Year Period. NeurosurgIcal Focus, 24, E9. https://doi.org/10.3171/FOC/2008/24/6/E9

[51] Ansari, M.K. and Jha, S. (2014) Tuberculoma Brain Abscess in an Immunocompe- 
tent Adolescent. Journal of Natural Science, Biology and Medicine, 5, 170-172. https://doi.org/10.4103/0976-9668.127319

[52] Brant-Zawadzki, M., Enzmann, D.R., Placone, R.C., et al (1983) NMR Imaging of Experimental Brain Abscess: Comparison with CT. American Journal of Neuroradiology, 4, 250-253.

[53] Chang, S.C., Lai, P.H., Chen, W.L., et al. (2002) Diffusion-Weighted MRI Features of Brain Abscess and Cystic or Necrotic Brain Tumors: Comparison with Conventional MRI. Clinical Imaging, 26, 227-236. https://doi.org/10.1016/S0899-7071(02)00436-9

[54] Martinez-Perez, I., Moreno, A., Alonso, J., et al. (1997) Diagnosis of Brain Abscess by Magnetic Resonance Spectroscopy: Report of Two Cases. Journal of Neurosurgery, 86, 708-713. https://doi.org/10.3171/jns.1997.86.4.0708

[55] Viale, G.L., Deseri, S., Gennaro, S., et al. (2002) A Craniocerebral Infectious Disease: Case Report as the Traces of Hippocrates. Neurosurgery, 50, 1376-1378. https://doi.org/10.1227/00006123-200206000-00034

[56] Boom, W.H. and Tuazon, C.U. (1985) Successful Treatment of Multiple Brain Abscesses with Antibiotics Alone. Reviews of Infectious Diseases, 7, 189-199. https://doi.org/10.1093/clinids/7.2.189

[57] Heineman, H.S., Braude, A.L. and Osterholm, J.L. (1971) Intracranial Suppurative Disease. Early Presumptive Diagnosis and Successful Treatment without Surgery. $J A M A, 218,1542-1547$. https://doi.org/10.1001/jama.1971.03190230038007

[58] Townsend, G.C. and Sheld, W.M. (1998) Infectious of the Central Nervous System. Advances in Internal Medicine, 43, 403-447.

[59] Bhatia, R., Tandon, P.N. and Banerji, A.K. (1973) Brain Abscess: An Analysis of 55 Cases. International Surgery Journal, 58, 565-568.

[60] Carpenter, J.L. (1994) Brain Stem Abscesses: Cure with Medical Therapy, Case Report, and Review. Clinical Infectious Diseases, 18, 219-226. https://doi.org/10.1093/clinids/18.2.219

[61] Chow, A.W., Alexander, E., Montgomerie, J.Z., et al. (1975) Successful Treatment of Non-Meningitic Listerial 1 Brain Abscess without Operation. Western Journal of Medicine, 122, 167-171.

[62] Ingham, H.R. and Selkon, J.B. (1982) Metronidazole and Brain Abscess. Lancet, 2, 613-614. https://doi.org/10.1016/S0140-6736(82)90695-X

[63] Seneviratne, S., Navasivayam, P., Perera, S. and Wickremasinghe, R.S. (2003) Microbiology of Cerebral Abscess at the Neurosurgical Unit of The National Hospital of Sri Lanka. Ceylon Medical Journal, 48, 14-16. https://doi.org/10.4038/cmj.v48i1.3388

[64] Raza, M.W., Shad, A., Pedler, S.J. and Karamat, K.A. (2005) Penetration and Activity of Antibiotics in Brain Abscess. Journal of College of Physicians and Surgeons Pakistan, 15, 165-167.

[65] Asensi, V., Carton, J.A. and Maradona, J.A. (1996) Imipenem Therapy of Brain Abscesses. European Journal of Clinical Microbiology \& Infectious Diseases, 15, 653-657. https://doi.org/10.1007/BF01691152

[66] Meis, J.F., Groot-Loonen, J. and HoogkamKorstanje, J.A. (1995) A Brain Abscess Due to Multiply-Resistant Enterobacter Cloacae Successfully Treated with Meropenem. Clinical Infectious Diseases, 20, 1567. https://doi.org/10.1093/clinids/20.6.1567

[67] Wessalowski, R., Thomas, L., Kivit, J., et al. (1993) Multiple Brain Abscesses Caused 
by Salmonella Enteritidis in a Neonate: Successful Treatment with Ciprofloxacin. The Pediatric Infectious Disease Journal, 12, 683-688. https://doi.org/10.1097/00006454-199308000-00010

[68] Moorthy, R.K. and Rajshekhar, V. (2003) Isolated Ring-Enhancing Lesion of the Brainstem in a Patient with Cyanotic Heart Disease: Role of Stereo-Tactic Intervention. Neurology India, 51, 404-406.

[69] Thom, S.R., Bhopale, V.M., Velazquez, O.C., Goldstein, L.J. Thom, L.H. and Buerk, D.G. (2006) Stem Cell Mobilization by Hperbaric Oxygen. American Journal of Physiology, Heart and Circulatory Physiology, 290, 1378-1386. https://doi.org/10.1152/ajpheart.00888.2005

[70] Kielian, T. (2004) Immunopathogenesis of Brain Abscess. Journal of Neuroinflammation, 1, 16. https://doi.org/10.1186/1742-2094-1-16

[71] Syed, M.M., Phyllips, N., et al. (2007) Minocycline Modulates Neuroinflammation Independently of Its Antimicrobial Activity in Staphylococcus Aureus-Induced Brain Abscess. The American Journal of Pathology, 171, 1199-1214. https://doi.org/10.2353/ajpath.2007.070231

[72] Naqash, I., Ahad, B., Zargar, J., Kirmani, A. and Wani, M. (2002) Anaesthetic Management of a Case of Tetralogy of Fallot for Drainage of Brain Abscess: A Case Report. The Internet Journal of Anesthesiology, 7, 1-4. https://doi.org/10.5580/116d

[73] Rosenblum, M.L., Mampalam, T.J. and Pons, V.G. (1986) Controversies in the Management of Brain Abscesses. Clinical Neurosurgery, 33, 603-632.

[74] Yildizhan, A., Pasaoglu, A. and Kandemir, B. (1989) Effect of Dexamethasone on Various Stages of Experimental Brain Abscess. Acta Neurochirurgica, 96, 141-148. https://doi.org/10.1007/BF01456174

[75] Lyons, B.E., Enzmann, D.R., Britt, R.H., et al. (1982) Short Term, High Dose Corticosteroids in Computed Tomographic Staging of Experimental Brain Abscess. Neuroradiology, 23, 279-284. https://doi.org/10.1007/BF00339395

[76] Kourtopoulos, H., Holm, S.E. and Norrby, S.R. (1983) The Influence of Steroids on the Penetration of Antibiotics into Brain Tissue and Brain Abscesses: An Experimental Study in Rats. Journal of Antimicrobial Chemotherapy, 11, 245-249. https://doi.org/10.1093/jac/11.3.245

[77] Chun, C.H., Johnson, J.D. and Hofstetter, M. (1986) Brain Abscess: A Study of 45 Consecutive Cases. Medicine, 65, 415-431. https://doi.org/10.1097/00005792-198611000-00006

[78] Seydoux, C. and Francioli, P. (1992) Bacterial Brain Abscesses: Factors Influencing Mortality and Sequelae. Clinical Infectious Diseases, 15, 394-401. https://doi.org/10.1093/clind/15.3.394

[79] Mampalam, T.J. and Rosenblum, M.L. (1988) Trends in the Management of Bacterial Brain Abscesses: A Review of 102 Cases over 17 Years. Neurosurgery, 23, 451-58. https://doi.org/10.1227/00006123-198810000-00008

[80] Yang, S.Y. and Zhao, C.S. (1993) Review of 140 Patients with Brain Abscess. Surgical Neurology, 39, 290-296. https://doi.org/10.1016/0090-3019(93)90008-O

[81] Canale, D.J. and William, M. (1996) The Treatment of Brain Abscess. Revisited After One Hundred Years. Journal of Neurosurgery, 84, 133-142. https://doi.org/10.3171/jns.1996.84.1.0133

[82] King, J.E. (1924) The Treatment of the Brain Abscess by Unroofing and Temporary Herniation of Abscess Cavity with Avoidance of Usual Drainage Methods, with Notes on the Management of Hernia Cerebri. General, Surgery, Gynecology \& Ob- 
stetrics, 39, 554-568.

[83] Dandy, W.E. (1926) Treatment of Chronic Abscesses of the Brain by Tapping, Preliminary Note. JAMA, 87, 1477-1478. https://doi.org/10.1001/jama.1926.02680180049012

[84] Sargent, P. (1928) Remarks on Drainage of Brain Abscess. British Medical Journal, 2, 971-972. https://doi.org/10.1136/bmj.2.3543.971

[85] Kocherry, X.G., Hegde, T., Sastry, K.V. and Mohanty, A. (2008) Efficacy of Stereotactic Aspiration in Deep-Seated and Eloquent-Region Intracranial Pyogenic Abscesses. Neurosurgical Focus, 24, E13. https://doi.org/10.3171/FOC/2008/24/6/E13

[86] Cohen, J.E., Mierez, R. and Tsai, E.C. (1999) Postcraniotomy Gas-Containing Brain Abscess: A Neurosurgical Emergency, Case Report. Surgical Neurology, 51, 568-570. https://doi.org/10.1016/S0090-3019(97)00498-9

[87] Mamelak, A.N., Obana, W.G., Flaherty, J.F., et al. (1994) Nocardial Brain Abscess: Treatment Strategies and Factors Influencing Outcome. Neurosurgery, 35, 622-631. https://doi.org/10.1227/00006123-199410000-00007

[88] Nadvi, S.S., Parboosing, R. and Van Dellen, J.R. (1997) Cerebellar Abscess: The Significance of Cerebrospinal Fluid Diversion. Neurosurgery, 41, 61-67. https://doi.org/10.1097/00006123-199707000-00013

[89] Kahn, E. (1937) The Treatment of Encapsulated Brain Abscess. JAMA, 108, 87-90. https://doi.org/10.1001/jama.1937.02780020005002

[90] Longatti, P., Perin, A., Ettorre, F., Fiorindi, A. and Baratto, V. (2006) Endoscopic Treatment of Brain Abscesses. Child s Nervous System, 22, 1447-1450. https://doi.org/10.1007/s00381-006-0119-2

[91] Fritsch, M. and Manwaring, K.H. (1997) Endoscopic Treatment of Brain Abscess in Children. Minimally Invasive Neurosurgery, 40, 103-106. https://doi.org/10.1055/s-2008-1053427

[92] Mahmood, A., Abad, R.M. and Updegrove, J.H. (1993) Brain Abscess Treated by Continuous Antibiotic Perfusion: Technical Note. Neurological Research, 15, 63-67. https://doi.org/10.1080/01616412.1993.11740110

[93] Yamamoto, M., Jimbo, M., Ide, M., et al. (1993) Penetration of Intravenous Antibiotics into Brain Abscesses. Neurosurgery, 33, 44-49. https://doi.org/10.1227/00006123-199307000-00007

[94] Hashizume, A., Kodama, Y., Hotta, T., et al. (1994) Brain Abscess Ruptured into the Lateral Ventricle: The Usefulness of Treatment by Intraventricular Irrigation with Antibiotics: A Case Report. Neurological Surgery, 22, 689-693.

[95] Takeshita, M., Kawamata, T., Izawa, M., et al. (2001) Prodromal Signs and Clinical Factors Influencing Outcome in Patients with Intraventricular Rupture of Purulent Brain Abscess. Neurosurgery, 48, 310-316. https://doi.org/10.1227/00006123-200102000-00012

[96] Zeidman, S.M., Geisler, F.H. and Olivi, A. (1995) Intraventricular Rupture of A Purulent Brain Abscess: Case Report. Neurosurgery, 36, 189-193. https://doi.org/10.1227/00006123-199501000-00026

[97] Choudhari, K.A. (2001) Prodromal Signs and Clinical Factors Influencing Outcome in Patients with Intraventricular Rupture of Purulent Brain Abscess. Neurosurgery, 49, 481-483. https://doi.org/10.1227/00006123-200108000-00056

[98] Nielsen, H., Gyldensted, C. and Harmsen, A. (1982) Cerebral Abscess: Etiology and Pathogenesis, Symptoms, Diagnosis and Treatment. A Review of 200 Cases from 
1935-1976. Acta Neurologica Scandinavica, 65, 609-622. https://doi.org/10.1111/j.1600-0404.1982.tb03114.x

[99] Legg, N.J., Gupta, P.C. and Scott, D.F. (1973) Epilepsy Following Cerebral Abscess, A Clinical and EEG Study of 70 Patients. Brain, 96, 259-268. https://doi.org/10.1093/brain/96.2.259

[100] Kurien, M., Job, A., Mathew, J. and Chandy, M. (1998) Otogenic Intracranial Abscess: Concurrent Craniotomy and Mastoidectomy-Changing Trends in a Developing Country. Archives of Otolaryngology-Head \& Neck Surgery, 124, 1353-1356. https://doi.org/10.1001/archotol.124.12.1353

[101] Rosenblum, M.L., Hoff, J.T., Norman, D., et al. (1980) Nonoperative Treatment of Brain Abscesses in Selected High-Risk Patients. Journal of Neurosurgery, 52, 217-225. https://doi.org/10.3171/jns.1980.52.2.0217

[102] Osenbach, R.K. and Loftus, C.M. (1992) Diagnosis and Management of Brain Abscess. Neurosurgery Clinics of North America, 3, 403-420. https://doi.org/10.1016/S1042-3680(18)30671-5

[103] MehnazAtiq, H., et al. (2006) Brain Abscess in Children. Indian Journal of Pediatrics, 73, 402. https://doi.org/10.1007/BF02790392

[104] O’Danoghue, M.A., Green, H.T. and Shaw, M.D. (1992) Cerebral Abscess on Merseyside 1980-1988. Journal of Infection, 25, 163-172. https://doi.org/10.1016/0163-4453(92)93989-4

[105] Whelan, M.A. and Hilal, S.K. (1980) Computed Tomography as a Guide in the Diagnosis and Follow-Up of Brain Abscesses. Radiology, 135, 663-671. https://doi.org/10.1148/radiology.135.3.7384453

[106] Dobkin, J.F., Healton, E.B., Dickinson, P.C., et al. (1984) Nonspecificity of Ring Enhancement in “Medically Cured” Brain Abscess. Neurology, 34, 139-144. https://doi.org/10.1212/WNL.34.2.139 